\title{
Arginine as a Significant Regulator of Supersaturation in Calcium Oxalate Lithiasis: the Physiological Evidence
}

\author{
Stoyanka Slavcheva Atanassova
}

\begin{abstract}
Background: At present, the possible effect of arginine as a natural regulator of calcium oxalate $(\mathrm{CaOX})$ supersaturation and crystallization in human urine has been analyzed.

Methods: Two types of experiments have been discussed: clinical laboratory analysis on the urine excretion of arginine (Arg) in patients with $\mathrm{CaOX}$ lithiasis and detailed measurements of the kinetics of the dissolution of $\mathrm{CaOX}$ calculi in artificial urine, containing various concentrations of Arg.

Results: A detailed analysis showed that $80 \%$ of stone formers (SFs) eliminated pathological values: $30 \%$ of patients had lower plasma levels compared to controls and about $50 \%$ of SFs showed higher concentration. Urine concentrations in these two groups were not reported.

Conclusions: The in vitro analytical measurements demonstrate even a possibility to dissolve $\mathrm{CaOX}$ stones in human urine, in which increased concentration of Arg has been established. Discussions have arisen to use increased concentration of Arg in urine both as a solubilizator of $\mathrm{CaOX}$ stones in humans and on the purpose of a prolonged metaphylactic treatment.
\end{abstract}

Keywords: Calcium oxalate calculi; Arginine; Dissolution of crystalline; Urine supersaturation

\section{Introduction}

The interest towards the formations of renal calculi can be explained by the wide speard of nephrolithiasis $[1,2]$ and that kind of stones is caused by some gastrointestinal diseses [3, 4]. Despite a number of promising hypotheses, the pathogenetic

Manuscript accepted for publication February 17, 2015

Department of Clinical Laboratory and Clinical Immunology, Medical University, Sofia 1431, Bulgaria. Email: stoyana_atanassova@abv.bg

doi: http://dx.doi.org/10.14740/wjnu199w mechanism of the intrarenal calcium oxalate $(\mathrm{CaOX})$ stone formation remains obscure; thus the clarification of the main physico-chemical moments of the processes of phase formation in human urine is of significant clinical importance.

In investigating the kinetics of crystal nucleation and growth, and the kinetics of the dissolution of already existing stones, of utmost significance are the issues related to the calculation of the level of supersaturation in biological solutions (such as urine). The urine's saturation is the driving force for the formation of the calculi and still cannot be regulated. In this conection, the results of this study could be put into practice in the clinical treatment of stone formations.

Of all the stone forming substances in the human urine, of most significance is the $\mathrm{CaOX}$ precipitation, both, because of the dissemination of the $\mathrm{CaOX}$ urolithiasis and because it is the most insoluble stone former (SF). It has to be noted that, in view of the dominant role of hypercalciuria in the pathogenesis of calcium stones [5-7], our therapeutic efforts in respect to those factors are neither clinically, nor scientifically satisfactory.

In recent years, it was shown that the supersaturation in the urine is determined not so much by the concentration of the ions $\left(\mathrm{Ca}^{2+}\right.$ and $\left.\mathrm{C}_{2} \mathrm{O}_{4}{ }^{2-}\right)$ constituting the concrements, but by the presence or absence of complex forming agents in the urine. It has been evident since Hammarsten's classic studies [8] that many ions, such as $\mathrm{Mg}^{2+}$, citrate or $\mathrm{HPO}_{4}{ }^{2-}$, which are normally present in the urine, increase the solubility of $\mathrm{CaOX}$ in aqueous solutions by forming complexes with either the $\mathrm{Ca}^{2+}$ or the $\mathrm{C}_{2} \mathrm{O}_{4}{ }^{2-}$ ions. However, the oral administration of these complexing agents does not lead to encouraging clinical results, as they metabolize quickly in the organism.

There has been an increasing interest, particularly, in Cabinding amino acids, due to their role in many calcium-dependent physiological processes. The possible inhibiting impact of various amino acids (alanine, ornithine, tryptophane, etc.) on the type of the $\mathrm{CaOX}$ formation and on the subsequent $\mathrm{CaOX}$ growth in the urine is often discussed in academic literature. The above mentioned amino acids, which are also common in the urine, have an inhibiting effect on the $\mathrm{CaOX}$ growth even at minimal concentration [9-11].

According to our in vitro data [12], arginine (Arg) is a weak complexing agent with respect to calcium. $\operatorname{Arg}\left(\mathrm{C}_{6} \mathrm{H}_{14} \mathrm{~N}_{4} \mathrm{O}_{2}\right)$ is present in the human urine at lower concentrations relative to other amino acids; its urine's excretion is 7.0 - $47.0 \mu \mathrm{mol} / 24$ 
h [13]. We found that in physiological solutions, resembling the human urine in their composition, the complexing effect of $\mathrm{L}-\mathrm{Arg}$ with respect to $\mathrm{Ca}^{2+}$ ions was surprisingly higher. Those preliminary results and the possible biological significance of Arg provided the impetus for a thorough examination of the kinetics of the $\mathrm{CaOX}$ concrements dissolution in physiological solutions containing various concentrations of acid.

Up to now, no analysis has been performed on the possible correlation between the Arg's concentration in the urine and the inclination to develop $\mathrm{CaOX}$ calculosis. The results obtained in our in vitro experiments [12] regarding the dissolution of $\mathrm{CaOX}$ in physiological solutions, containing an increased concentration of Arg, stress the importance of those analyses.

\section{Patients and Methods}

Two types of experiments were performed in the framework of this investigation: 1) analysis on the concentration of the Arg in serum and urine in patients with $\mathrm{CaOX}$ stones, as well as, in a healthy control group; and 2) an investigation on the kinetics of dissolution of $\mathrm{CaOX}$ calculi in physiological solutions, containing various concentrations of Arg.

\section{Patient studies}

SFS

Fifty-six patients (30 men and 26 women) were included, whose age ranged from 14 to 65 years, at the beginning of the calculosis, and who had had their $\mathrm{CaOX}$ renal calculi removed spontaneously, by surgery or through extracorporeal shockwave lithotripsy (ESWL). Each patient had a known clinical and family history of this disease, including data for episodes of a renal colic and of concrements elimination, the presence of metabolic disorders and so forth. During the conduction of the study, the patients were on free diet and fully compensated renal function. They did not report any liver disease.

\section{Controls}

Fifteen healthy subjects were included who never had any urological and hepatic trouble.

\section{Calculi}

The calculi were taken at random from patients who had undergone surgical or ESWL removal of the stones.

\section{Methods}

A 24-h urine collection was obtained from each patient. During the period of urine collection, specimens were refrigerated and aliquots of the 24-h volume and sample were immediately frozen until analyzed. The volume of urine in every sample was recorder on completion of the collection and $\mathrm{pH}$ was measured by using a glass electrode $\mathrm{pH}$-meter.

Serum was obtained from the same patients as those whose urine was collected from. Heparinized plasma was separated by centrifugation and was also stored at temperature $-25^{\circ} \mathrm{C}$.

The amino acid (Arg) contents of the sample were determined using a Hewlett Packard HPLC 1050, coupled to a fluorescence detector. Ethyl alcohol was added to the urine specimens to allow the precipitation of proteins and the extraction of free amino acids. An automated precolumn orthophtalaldehyde derivation procedure was employed. Separations were done using a reversed-phase column (Waters Corp). Amino acid concentration of the samples was determined by comparison with values obtained from a standard curve. Amino acid concentrations are expressed in $\mu \mathrm{M}$.

The amino acid (Arg) in urinary calculi was evaluated as follows. The calculi were carefully rinsed in saline to remove any contaminations (blood clots, etc). The calculi were dried with filter paper and ground into a powder in an agate mortar. To $0.5 \mathrm{~g}$ of the powder, $4.5 \mathrm{~mL} 90 \%$ ethyl alcohol were added, well mixed and left for $10 \mathrm{~min}$ to allow the precipitation of proteins and extraction of free amino acids and then centrifuged. The supernatant was evaporated to dryness under vacuum at a temperature not exceeding $55^{\circ} \mathrm{C}$. The residue was re-dissolved in $0.2 \mathrm{~mL} \mathrm{10 \%} \mathrm{isopropyl} \mathrm{alcohol.} \mathrm{The} \mathrm{qualitative}$ analysis of the calculi was carried out by the HPLC.

\section{Statistical analysis}

Statistical analysis of the data obtained from both the SF patients and from the control group was performed using Student's $t$-test to establish the significance of the difference between mean values. All results were expressed as mean $\pm \mathrm{SEM}$ and the differences were considered significant if $\mathrm{P}<0.05$.

\section{Dissolution of $\mathrm{CaOX}$ concrement: basic theoretical con- siderations}

Human urine is a complicated physiological solution. The physic-chemical formalism of the kinetics of dissolution of kidney stones has been developed, in details, in our papers $[14,15]$. One can see that simple formulae can be obtained, describing the effect of complex forming agents (present in the solution at various concentrations) on supersaturation, solubility, and growth velocity of $\mathrm{CaOX}$ crystals growing or dissolving in solution, resembling human urine. It can be shown that if we introduce an increasing concentration $\mathrm{C}_{\mathrm{Arg}}$ (e.g. Larginine) of a $\mathrm{Ca}^{2+}$ - binding complex forming agent, having a solubility constant $\mathrm{K}_{\text {Arg }}$ into the solution, a linear dependence between the solubility $\mathrm{S}_{\mathrm{Arg}}$ and $\mathrm{C}_{\mathrm{Arg}}$ for $\mathrm{Ca}^{2+}>>\mathrm{C}_{2} \mathrm{O}_{4}{ }^{2-}$ can be predicted by:

$\mathrm{S}_{\mathrm{Arg}}=\mathrm{S}\left(1+\mathrm{K}_{\mathrm{Arg}} \mathrm{C}_{\mathrm{Arg}} / \alpha^{\prime}\right)(1)$

where $\alpha^{\prime}$ is the $\alpha$ factor in the absence of the complex forming agent "Arg" (here indicating L-arginine).

Thus, the dependence of the supersaturation $\Delta \mu$ on $\mathrm{C}_{\mathrm{Arg}}$ 
Table 1. Serum Levels and Urine Excretions of Amino Acid Arginine in the Patients With a Calcium Oxalate Calculosis and Control Group [13]

\begin{tabular}{llll} 
& Ref. value [13] & Controls $(\mathbf{n}=\mathbf{1 5})$ & Stone formers $(\mathbf{n}=\mathbf{5 6})$ \\
\hline Arginine, $\mathrm{x}(\mu \mathrm{mol} / \mathrm{L})$ (in serum) & $49.7-132.1$ (Male) & $94.7 \pm 54.5$ & $109.9 \pm 39.4$ \\
& $46.9-139.7$ (Female) & & - \\
\hline Arginine, $x(\mu \mathrm{mol} / 24 \mathrm{~h})$ (in urine) & $7-47$ & - & - \\
\hline
\end{tabular}

for the physiologically significant case $\mathrm{Ca}^{2+}>\mathrm{C}_{2} \mathrm{O}_{4}{ }^{2-}$, determining the supersaturation in urine is:

$$
\Delta \mu \cong \Delta \mu_{\mathrm{o}}-1 / 2 \ln \left(\mathrm{K}_{\mathrm{Arg}} \mathrm{C}_{\mathrm{Arg}} / \alpha^{\prime}\right)(2)
$$

where $\Delta \mu_{\mathrm{o}}$ is the supersaturation in respect to the $\mathrm{CaOX}$ precipitation without Arg added.

It is also of interest that in the case of the dissolution of $\mathrm{CaOX}$ concrements in the presence of a fixed initial concentration of $\mathrm{CaOX}$ (or, which in the case of $\mathrm{Ca}^{2+}>>\mathrm{C}_{2} \mathrm{O}_{4}{ }^{2-}$ is the same, in the presence of constant concentration $\mathrm{C}_{\mathrm{o}}{ }^{*}$ of oxalic anions) we have to rewrite (1) as follows:

$\mathrm{S}_{\mathrm{Arg}}=\mathrm{S}\left(1+\mathrm{K}_{\mathrm{Arg}} \mathrm{C}_{\mathrm{Arg}} / \alpha^{\prime}\right)-\mathrm{C}_{\mathrm{o}} *$ (3)

Thus a plot of $\mathrm{S}_{\mathrm{Arg}}$ versus $\mathrm{C}_{\mathrm{Arg}}$ should result in a straight line with a slope of $-\mathrm{SK}_{\mathrm{Arg}} / \alpha$, cutting from the ordinate axis a segment $\mathrm{S}_{\mathrm{Arg}}(\mathrm{O})=\mathrm{S}-\mathrm{C}_{\mathrm{o}}$ *. In this way, both $\mathrm{S}_{\mathrm{Arg}}$ and $\mathrm{K}_{\mathrm{Arg}}$ can be determined at a known value of $\alpha$ (according to data in Robertson et al [16], $\alpha$ ' in human urine is approximately 2).

Thus, depending on the concentration $\mathrm{C}_{\mathrm{Arg}}$, that is, on the sign of $\Delta \mu$ (i.e. $\Delta \mu>0$ during growth, $\Delta \mu<0$ during dissolution), growth or dissolution of $\mathrm{CaOX}$ concrements can be achieved simply by changing the concentration $\mathrm{C}_{\mathrm{Arg}}$ of the $\mathrm{Arg}$ added.

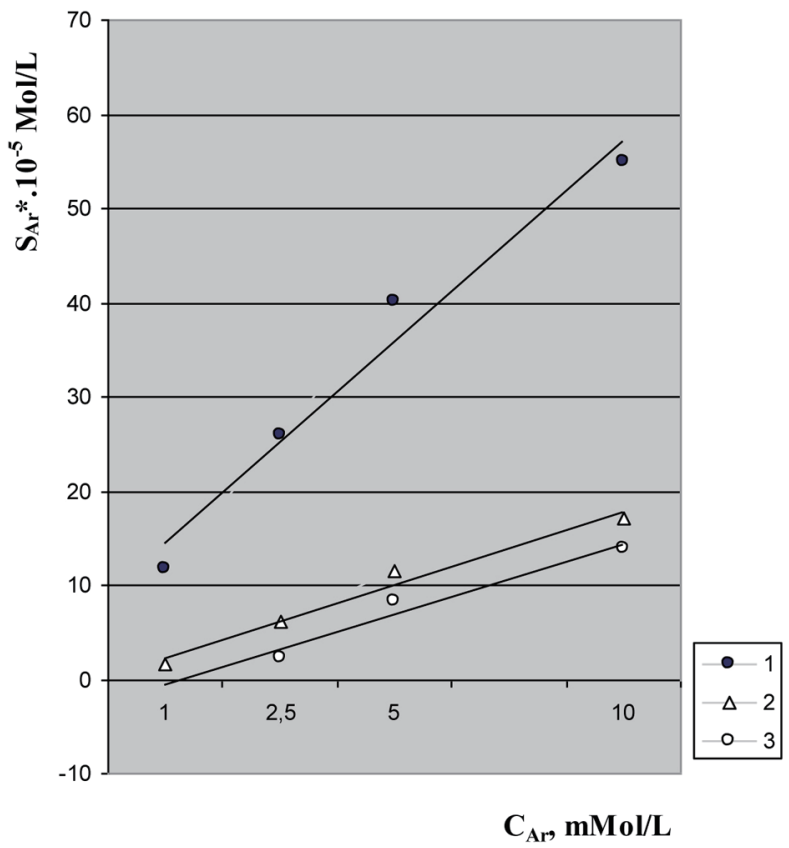

Figure 1. Solubility of calcium oxalate calculi in artificial urine as a function of L-arginine concentration. Solubility in zero saturation urine (curve 1). Solubility in artificial urine with lower saturation (curve 2). Solubility in artificial urine with normal saturation (curve 3 ).

\section{Instrumental techniques}

The experiments on the kinetics of the dissolution of $\mathrm{CaOX}$ renal calculi were performed in Jena glass round bottom flasks thermostated at $25^{\circ} \mathrm{C}$. The volume of the studied solution was $1,000 \mathrm{~mL}$ and it was stirred (about $200 \mathrm{rpm}$ ) by an electromagnetic stirrer. The Archimedean weight G (t) of the samples of $\mathrm{CaOX}$ calculi, put in a platinum net basket and suspended to a torsion balance, was continuously measured with a sensitivity of $\pm 0.5 \mathrm{mg}[14,15]$.

The $\mathrm{CaOX}$ calculi used had been formed in the urinary tract and eliminated spontaneously by the patients. The calculi were selected to have a weight of 100 to $200 \mathrm{mg}$ and to be of identical mineral composition, mainly $\mathrm{CaC}_{2} \mathrm{O}_{4} \cdot 2 \mathrm{H}_{2} \mathrm{O}$ (weddellite). The composition of the calculi was checked by polarizedlight microscopy and thermogravimetry (DTG).

We employed two different types of aqueous solutions, mimicking urine $[17,18]$, with our solvent (Arg) introduced in several different concentrations.

\section{Results}

\section{Clinical laboratory data}

Table 1 [13] shows the plasma levels $(\mu \mathrm{mol} / \mathrm{L})$ and the urine excretion $(\mu \mathrm{mol} / 24 \mathrm{~h})$ of amino acid Arg in the groups of the patients (SFs) and control subjects. A mathematical estimation of the deviation from the observations on amino acid in patients has been made.

Thus, plasma levels of Arg in the patients were non-significantly higher compared to those of a control group. A detailed analysis shows that $80 \%$ of SFs eliminated pathological values: $30 \%$ of patients had lower plasma levels compared to controls and about $50 \%$ of SFs showed higher concentration. ed.

Urine concentrations in these two groups were not report-

\section{Data of in vitro experiments}

The solubility of $\mathrm{CaOX}$ in artificial urine with zero supersaturation is considerably increased $\left(8.7 \times 10^{-5} \mathrm{~mol} / \mathrm{L}\right)$ compared with its solubility in pure water $\left(5.5 \times 10^{-5} \mathrm{~mol} / \mathrm{L}\right)$ due to the presence of complexing ions $\left(\mathrm{Mg}^{2+}\right.$, citrate ions, etc.) in this solution as predicted by $\alpha_{i}$ coefficients known from an analytical chemistry $[8,14]$. When L-Arg is introduced into the same physiological solution, a dramatic change in solubility (up to 
Table 2. L-Arginine as a Solvent of Calcium Oxalate: Comparison With Classical Complex Forming Agents [8, 14, 16]

\begin{tabular}{|c|c|c|c|c|c|c|}
\hline Ligand & Complex former & Solution & $\mathrm{T}\left({ }^{\circ} \mathrm{C}\right)$ & pH & $\mathrm{K}_{\mathrm{i}}(\mathrm{L} / \mathrm{mol})$ & Reference \\
\hline $\mathrm{C}_{2} \mathrm{O}_{4}^{2-}$ & $\mathrm{Mg}^{2+}$ & $0.3 \mathrm{M} \mathrm{NaCl}$ & 25 & 5.0 & $4.0 \times 10^{3}$ & {$[8]$} \\
\hline $\mathrm{C}_{2} \mathrm{O}_{4}^{2-}$ & $\mathrm{Mg}^{2+}$ & $0.3 \mathrm{M} \mathrm{NaCl}$ & 37 & - & $5.6 \times 10^{3}$ & {$[14]$} \\
\hline Na-EDTA & $\mathrm{Ca}^{2+}$ & Physiological solution & 25 & 7.0 & $5.0 \times 10^{5}$ & {$[14]$} \\
\hline Citric anion & $\mathrm{Ca}^{2+}$ & Pure water & 25 & - & $5.0 \times 10^{2}$ & {$[16]$} \\
\hline L-arginine & $\mathrm{Ca}^{2+}$ & 0 -artificial urine & 25 & 5.4 & $5.6 \times 10^{3}$ & Fig. 1 \\
\hline
\end{tabular}

$55 \times 10^{-5} \mathrm{~mol} / \mathrm{L}$ (i.e. about $70 \mathrm{mg} / \mathrm{L}$ ) is observed, as shown in Fig. 1.

A similar effect of L-Arg is also seen in artificial urine, in which distinct supersaturation (due to the presence of a normal concentration of $\mathrm{Ca}^{2+}$ and a medium concentration of $\mathrm{C}_{2} \mathrm{O}_{4}{ }^{2-}$ ions [12]) has been maintained (Fig. 1, curves 2 and 3).

In accordance with Eq (1), a linear dependence of the solubility on $\mathrm{C}_{\text {Arg. }}$ is observed (Fig. 1) for each series of measurements, in which three different supersaturation values (zero, medium and normal) have been established. The effect of the increasing concentration of L-Arg on the solubility of $\mathrm{CaOX}$ crystals is clearly evident; the initially supersaturated solutions are transformed into undersaturated systems. The effect of the presence of $\mathrm{Ca}^{2+}$ of the course of the straight lines 2 and 3 in Fig. 1 when compared with the no- $\mathrm{Ca}^{2+}$ case (line 1 in the same figure) is to be noted. A sharp decrease in the slope of lines 2 and 3 is observed, too. Since the two solutions have the same $\mathrm{Ca}^{2+}$ concentration, curves 2 and 3 are parallel, as expected from the formalism, as discussed above [14].

\section{Discussion}

This paper examines the role and place of the amino acid Arg in the pathogenesis of $\mathrm{CaOX}$ renal calculosis. It has been found that Arg is a very effective solvent of $\mathrm{CaOX}$ calculi in solutions characterized by the composition and ionic strength of human urine. We have found that the mechanism of dissolution of $\mathrm{CaOX}$ calculi follows the Nernst model of a diffusionlimited process as it is discussed in detail in literature $[12,14$, 15]. The dissolution of $\mathrm{CaOX}$ with $\mathrm{Arg}$ is a relatively slow process, taking approximately 1 month to dissolve about a $70 \mathrm{mg}$ sample at zero supersaturation. Detailed analysis performed in our study indicates that Arg is comparable, in its solubility effect, to the best known classical complex binders of $\mathrm{Ca}^{2+}$ or $\mathrm{C}_{2} \mathrm{O}_{4}{ }^{2-}$ ions in urine, that is, $\mathrm{Mg}^{2+}$ and citrate anions. This can be seen from Table $2[8,14,16]$, in which the stability constant $\mathrm{K}_{\mathrm{Arg}}$ of Arg calculated in our results (Fig. 1, Eq. 1) is compared to the $\mathrm{K}_{\mathrm{i}}$ values of $\mathrm{Mg}^{2+}$, Na-EDTA, and other known complex-formers of $\mathrm{CaOX}$.

Arg is one of the amino acids constituent of normal human urine. Arg is found in all proteins, which means that it is necessary for life. From bases and arginaza enzyme, which is found in the liver, it breaks down into urea and ornithine (ornithine cycle). The addition of Arg can reduce the binding of free radicals in tubular membranes, respectively to reduce nephrocalcinosis [19, 20].
Insignificantly higher are the serum levels of Arg $\left((\mathrm{NH})_{2} \mathrm{C}\left(\mathrm{NH}_{2}\right) \mathrm{CH}_{2} \mathrm{CH}_{2} \mathrm{CH}_{2} \mathrm{CH}\left(\mathrm{NH}_{2}\right) \mathrm{COOH}\right)$ for the patients to a $\mathrm{CaOX}$ lithiasis compared to control group. Of all finded free amino acids in $\mathrm{CaOX}$ stones, Arg is amino acid with highest frequency - $21.6 \mathrm{nmol} / \mathrm{mL}$. But do not expect that fact alone may explain the lack of Arg in urine collections. One possible explanation of this is the disintegration of the acid by the action of the enzyme arginaza to ornithine $\left(\mathrm{H}_{2} \mathrm{NCH}_{2} \mathrm{CH}_{2} \mathrm{CH}_{2} \mathrm{CH}\left(\mathrm{NH}_{2}\right) \mathrm{COOH}\right)$, i.e. we cannot consider separately excretion of ornithine from Arg's metabolism. On the other hand, free acid ornithine is not detected into the proteins, i.e. it is the main "body" of the amino acid Arg. Ornithine is the amino acid with a clearly complex action [21] and in this context, lower urinary excretion of ornithine (more than $60 \%$ of patients [22]) may explain low inhibitory activity of urine of these patients. From the analytical chemistry, it is known that the ornithine is an agent forming complex compound with metals (for example, calcium) leading to lower levels of urine saturation in unaffected patients.

Arg was not detected in the urine of patients with $\mathrm{CaOX}$ stones. The absence of this acid in groups of CaOX-SFs is of great interest, especially in light of non-difference Arg levels in the plasma of SFs and controls. More so than $30 \%$ of patients with $\mathrm{CaOX}$ stones have significantly lower plasma levels of Arg in relation to control group. The increased concentration of Arg in the urine of these patients would have a positive impact on the prophylaxis and therapeutic effects of our preventive treatment. The latter is of high importance, especially due to the fact that Arg is very similar in structure to proven complexing agents, such as ornithine, Na-EDTA (complexon III), etc.

This paper does not discuss the metabolic pathway of the Arginine.

\section{Conclusion}

The results of present study of Arg indicate a level of stone growth dissolution that considerably surpasses the one of any other amino acid. Our analysis proves that the positive impact of $\mathrm{Arg}$ on the $\mathrm{CaOX}$ dissolution is mainly due to the lower supersaturation of human urine, as a result of the administration of the agent. The "injection" of Arg to the human body through medication or diet could very effectively prevent the formation or further development of $\mathrm{CaOX}$ stones. Thus, we have assigned to Arg a promising place among the major solvents of $\mathrm{CaOX}$ calculi. 


\section{Disclosure}

All the authors declared no competing interests.

\section{References}

1. Ramello A, Vitale C, Marangella M. Epidemiology of nephrolithiasis. J Nephrol. 2000;13(Suppl 3):S45-50.

2. Robertson WG. Renal stones in the tropics. Semin Nephrol. 2003;23(1):77-87.

3. Binder HJ. Intestinal oxalate absorption. Gastroenterology. 1974;67(3):441-446.

4. Grases F, Costa-Bauza A, Prieto RM. Renal lithiasis and nutrition. Nutr J. 2006;5:23.

5. Tiselius HG. A hypothesis of calcium stone formation: an interpretation of stone research during the past decades. Urol Res. 2011;39(4):231-243.

6. Messa P, Marangella M, Paganin L, Codardini M, Cruciatti A, Turrin D, Filiberto Z, et al. Different dietary calcium intake and relative supersaturation of calcium oxalate in the urine of patients forming renal stones. Clin Sci (Lond). 1997;93(3):257-263.

7. Baumann JM, Affolter B, Caprez U, Henze U. Calcium oxalate aggregation in whole urine, new aspects of calcium stone formation and metaphylaxis. Eur Urol. 2003;43(4):421-425.

8. Hammarsten G. On calcium oxalate and its solubility in the presence of inorganic salts with special reference to the occurrence of oxaluria. Comp-Rend Trav, Laboratoire Carlsberg: Copenhagen. 1921;17:1-29.

9. Chow FC, Dysart MI, Hamar DW, Udall RH. Control of oxalate urolithiasis by DL-alanine. Invest Urol. 1975;13(2):113-116.

10. Grimm U, Steinhauser I, Wulff K, Knapp A, Zschiesche M. Studies on tryptophan metabolism in calcium oxalate urolithiasis. Z Urol Nephrol. 1988;81(5):299-303.

11. Fleming DE, van Bronswijk W, Ryall RL. A compara- tive study of the adsorption of amino acids on to calcium minerals found in renal calculi. Clin Sci (Lond). 2001;101(2):159-168.

12. Atanassova S. Solubility and dissolution kinetics of calcium oxalate renal calculi in solutions, containing L-arginine: in-vitro experiments. J Crystal Growth. 2010;312:1940-1944.

13. Boshev N. The biological constants in humans (in bulg). State Publishing House, Med i Fizk: Sofia. 1986:387-406.

14. Gutzow I, Atanassova S, Budevsky G. Kinetics of dissolution of calcium oxalate calculi in physiological solutions containing Hippuric acid. Cryst Res \& Technol. 1991;26(5):533-554.

15. Gutzow I, Atanassova S, Neykov K. Solubility and Crystallization in biological fluids and the problems of life and health. Pure Apply Chem. 2002;74(10):1785-1792.

16. Robertson WG, Peacock M, Nordin BE. Activity products in stone-forming and non-stone-forming urine. Clin Sci. 1968;34(3):579-594.

17. Doremus RH, Teich S, Silvis PX. Crystallization of calcium oxalate from synthetic urine. Invest Urol. 1978;15(6):469-472 .

18. Leskovar P. Methoden und Techniken zum Erfassen der Kristalle in Wassrigen Losungen, unter besonderer Berucksichtigung der Problemstellugen in der Harnsteinforschung. Aktuell Nephrol. 1979;12:149-175.

19. Ozturk H, Yagmur Y, Buyukbayram H. The effect of Larginine methyl ester on indices of free radical involvement in a rat model of experimental nephrocalcinosis. Urol Res. 2006;34(5):305-314.

20. Pragasam V, Kalaiselvi P, Sumitra K, Srinivasan S, Varalakshmi P. Counteraction of oxalate induced nitrosative stress by supplementation of 1-arginine, a potent antilithic agent. Clin Chim Acta. 2005;354(1-2):159-166.

21. Budevsky O. Foundation of chemical analysis. John Wiley \& Sons: NY. 1979.

22. Atanassova SS, Panchev P, Ivanova M. Plasma levels and urinary excretion of amino acids by subjects with renal calculi. Amino Acids. 2010;38(5):1277-1282. 